\title{
Educação midiática para notícias: histórico e mapeamento de iniciativas para combater a desinformação por meio da educação
}

\section{Media education and news: Historical background and measures to combat misinformation in schools}

\author{
Mônica CHAVES ${ }^{1}$ \\ Luísa MELO ${ }^{2}$
}

\section{Resumo}

Este artigo discute o conceito de educação midiática à luz dos problemas trazidos pela disseminação de conteúdos falsos no ambiente digital. Além disso, apresenta um histórico da educação midiática e apresenta achados preliminares de uma pesquisa realizada com professores/as de educação básica. Conclui-se que a preocupação em relação à educação midiática para notícias precisa ser apoiada pela comunidade escolar, sob pena de as futuras gerações viverem em uma sociedade em que as ciências como conhecimento compartilhado sejam desacreditadas, bem como a própria escola como instância em que este conhecimento é ensinado.

Palavras-chave: Desinformação; fake news; educação midiática, news literacy.

\begin{abstract}
This article addresses the concept of media education, taking into consideration the problems generated by the dissemination of fake news in digital environments. Additionally, we present a historical background on media education and discuss preliminary findings that stem from teachers that work in the basic education sector. We conclude that the concern that revolves around media education and news must be supported by the school community, otherwise, the future generations will live in a

\footnotetext{
1 Mestra pelo Programa de Pós-Graduação em Comunicação Social, Departamento de Comunicação, Pontifícia Universidade Católica do Rio de Janeiro. Membro do Grupo de Pesquisa em Interações Digitais da PUC-Rio. E-mail: contato@monicachaves.jor.br

2 Doutora em Literatura Comparada pela Universidade do Estado do Rio de Janeiro. Professora agregada da Pontifícia Universidade Católica do Rio de Janeiro. Pesquisadora do LabMid/PUC-Rio e membro do Grupo de Pesquisa em Interações Digitais e do Grupo de Pesquisa em Narrativas da Vida Moderna na Cultura Midiática da PUC-Rio e da Media Ecology Association (MEA). E-mail: luisamelo@mac.com
} 
society in which science, as shared knowledge, will lose credibility. This can also happen with the institution of schools themselves in which such knowledge is taught.

Keywords: Misinformation; fake news; media education, news literacy.

\section{Introdução}

As mudanças nos modos de veiculação de notícias ocorridas a partir da consolidação da comunicação digital trouxeram à tona questões decorrentes da crescente dificuldade de se diferenciar conteúdos confiáveis de histórias falsas ${ }^{3}$. É claro que a disseminação de boatos e acusações falsas não é um fenômeno novo: o historiador Robert Darnton (2017) mapeou exemplos que remontam a 1.500 anos atrás, como os ataques de Procópio ao imperador Justiniano no século VI; as "pasquinadas", surgidas em $1522 \mathrm{em}$ Roma com o objetivo de manipular uma eleição papal; e os canards franceses, no século XVII. Em Londres, até hoje são célebres os tabloides especializados na publicação de notícias difamatórias contra políticos, celebridades e membros da monarquia.

O que há de singular na forma como percebemos este fenômeno na era digital são as especificidades trazidas pelos ambientes criados pelas tecnologias de informação e comunicação e suas consequências, muitas delas não previstas, nos modos de interação, nos circuitos comunicativos e na própria vida social. O amplo acesso a dispositivos digitais que permitem o recebimento, o armazenamento, a edição e a distribuição de conteúdos audiovisuais por potencialmente qualquer indivíduo fez com que a preocupação com as consequências da desinformação para a vida social passasse a ocupar um papel central no debate público nos últimos anos, especialmente depois que políticos começaram a ser eleitos usando táticas de guerra de informações como estratégia eleitoral.

Vale observar que esse contexto se entrelaça a uma crise de credibilidade no jornalismo. As mudanças que estão em curso no modelo de veiculação de notícias se inter-relacionam a uma crise do papel social do jornalista, e, consequentemente, do

\footnotetext{
${ }^{3}$ Por questões conceituais, evitamos o uso tanto do termo êmico "fake news" quanto de sua tradução mais comum, a expressão "notícias falsas". Além de serem termos que não descrevem de forma adequada toda a complexidade do fenômeno da desinformação, acreditamos ser necessária a problematização do uso da palavra "notícia", por definição um relato sobre algo que aconteceu, junto ao adjetivo "falsas". Assim, neste trabalho os conteúdos enganosos, falsificados ou manipulados, emicamente conhecidos como "fake news" são referidos pelo termo histórias falsas.
} 


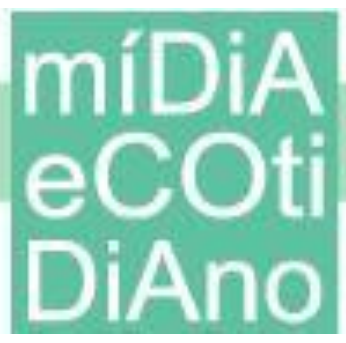

jornalismo. Segundo Adriana Braga, Leonel Aguiar e Mara Bergamaschi (2014), as mudanças estruturais na sociedade contemporânea trouxeram novos modos de produção dos conteúdos informativos, o que, por sua vez, teve impacto nos pressupostos da formação profissional dos jornalistas (BRAGA; AGUIAR; BERGAMASCHI, 2014, p.116). Assim, é possível afirmar que há um questionamento do contrato social que outorgou à imprensa, nos últimos dois séculos, a chancela da credibilidade. No entanto, cabe diferenciar os erros cometidos pelo mau jornalismo (erros de apuração ou de avaliação, sensacionalismo, falta de equilíbrio no relato dos fatos e interesses pessoais ou corporativos) das estratégias associadas à desinformação (histórias fictícias que se apresentam como se fossem relatos noticiosos).

Diante deste cenário, o relatório do Reuters Institute sobre mídias digitais mediu pela primeira vez, em 2018, a chamada news literacy - ou seja, a habilidade de analisar criticamente notícias e informações que as pessoas recebem por diferentes fontes. A conclusão foi que indivíduos com níveis mais altos de competências em news literacy tendem a preferir notícias de grandes jornais e usam as redes sociais da internet de modo diferente dos demais usuários. Por exemplo, ao decidir se irão clicar em uma notícia, prestam mais atenção a pistas sobre a credibilidade do conteúdo: em que veículo foi publicado, quem foi o autor, quem compartilhou o link, entre outras. Já para os indivíduos com menor competência em news literacy o mero número de comentários, curtidas e compartilhamentos parece ter mais importância no momento de avaliar a confiabilidade da notícia. Ou seja, enquanto um grupo busca critérios qualitativos ao compartilhar notícias, o outro se baseia em dados quantitativos, o que, naturalmente, não é suficiente para avaliar a veracidade de uma informação.

Na edição de 2019, o Instituto voltou a verificar o impacto das iniciativas de educação midiática para notícias nos 38 países pesquisados. Desta vez, o relatório apontou o crescimento da afinidade dos indivíduos pesquisados com fontes de notícias "mais conceituadas" e a queda do compartilhamento de conteúdos "menos confiáveis". O Brasil aparece como um dos destaques no que diz respeito ao aumento da confiança em fontes de notícias conceituadas em relação ao ano anterior, tendo a proporção dos que usam fontes deste tipo para obter informações noticiosas atingido o patamar de $36 \%$. Aqui, a preocupação com os efeitos da desinformação pode ser percebida no alto índice 




de respondentes que decidiram não compartilhar conteúdos potencialmente falsos (61\%). Segundo o relatório, "o comportamento parece ter mudado principalmente em países onde a preocupação com a desinformação é mais alta" ${ }^{4 "}$ (REUTERS INSTITUTE, 2019, p.23).

Neste artigo, iremos apresentar alguns conceitos relacionados à disseminação de conteúdos falsos no ambiente digital, especialmente aqueles ligados ao fenômeno que os pesquisadores Claire Wardle e Hossein Derakhshan (2017) chamam de desordem da informação. Em seguida, discutiremos o conceito de alfabetização ou educação midiática que, segundo diversos pesquisadores e organismos internacionais, é fundamental para o desenvolvimento de competências específicas de leitura crítica das mídias frente ao aumento da dificuldade de diferenciar notícias reais de conteúdos falsificados. Também apresentaremos um breve histórico das iniciativas nesse sentido. Por fim, compartilharemos os principais achados de uma pesquisa tipo survey realizada com professores/as de educação básica no Brasil com o objetivo de identificar se a educação midiática para notícias é uma preocupação dos docentes e dirigentes de escolas e se há ações do tipo planejadas ou em curso. A pesquisa foi aplicada por meio de formulário online, e a amostra foi selecionada por meio de grupos de professores existentes nas redes sociais da internet.

\section{Desordem da informação e desinformação como estratégia}

$\mathrm{Na}$ era digital, a disseminação em larga escala de conteúdos produzidos por não-profissionais com aparência de jornalismo torna cada vez mais difícil a avaliação sobre sua veracidade. Diante deste cenário, cresce a preocupação com a distribuição de informações erradas, descontextualizadas, distorcidas ou falsificadas. Ao conceituar o fenômeno denominado desordem da informação, Claire Wardle e Hossein Derakhshan partem de duas dimensões: danos e incorreções. O autor e a autora apresentam três tipos de informações que constituem o problema (WARDLE; DERAKHSHAN, 2017, p.5):

Mis-information, ou informação incorreta: informações falsas compartilhadas sem o objetivo de causar dano;

\footnotetext{
${ }^{4}$ Tradução livre. No original: Behaviour seems to have changed most in countries where concern about misinformation is highest.
} 
Dis-information ou informação falsificada: informações falsas compartilhadas, sabendo-se que são falsas, com a intenção de causar dano.

Mal-information ou má informação: informação genuína compartilhada para causar dano, em geral movendo informação que deveria ser privada para a esfera pública 5 .

$\mathrm{O}$ autor e a autora atribuem a crescente dificuldade de as pessoas avaliarem a credibilidade de uma mensagem ao modo como as redes sociais da internet mais populares se constituíram. Isso ocorre porque "postagens de publicações tão diferentes quanto o New York Times e um site de teorias da conspiração têm aparência quase

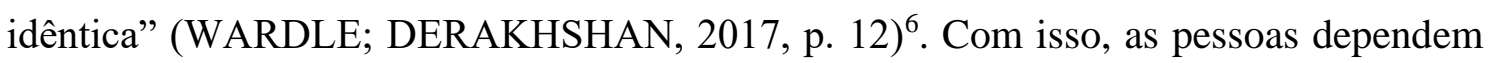
cada vez mais de amigos/as e da família para endossar as informações que se disseminam nas redes sociais da internet. Antigos hábitos de leitura, de quando as notícias eram filtradas por jornalistas aos quais era atribuída a função de gatekeepers da informação (WHITE, 1993), não valem mais em um ambiente em que o foco deixa de ser a fonte da notícia e passa a ser o modo como ela chega ao/à leitor/a (WARDLE; DERAKHSHAN, 2017, p.13).

A desconfiança e a confusão sobre quais fontes de informação são autênticas é, em sua avaliação, em muitos casos provocada intencionalmente, no que consideram ser “campanhas de desinformação". As eleições norte-americanas de 2016, com a vitória de Donald Trump, foram um ponto crítico no que diz respeito à preocupação mundial com o fenômeno da desinformação. Não à toa a "palavra do ano" escolhida pelo dicionário Oxford naquele momento foi post-truth, ou pós-verdade ${ }^{7}$.

\footnotetext{
${ }^{5}$ É importante observar que em português não há palavras diferentes para estes termos. Tanto o dicionário Cambridge quanto o Michaelis traduzem misinformation como informação incorreta/falsificada e disinformation como desinformação, sendo que o Cambridge usa esta última tradução para os dois termos em inglês. Diante da dificuldade de diferenciá-los em português de forma tão clara, neste trabalho adotamos o conceito de desinformação para tratar de forma abrangente dos três tipos de informação discutidas por Wardle e Derakhshan (2017).

${ }^{6}$ Tradução livre. No original, o trecho completo é: Another critical point is that popular social networks make it difficult for people to judge the credibility of any message, because posts from publications as unlike as the New York Times and a conspiracy site look nearly identical.

${ }^{7}$ A definição do dicionário para o termo post-truth é: relating to a situation in which people are more likely to accept an argument based on their emotions and beliefs, rather than one based on facts (ou, em
} 
Assim, boatos, teorias da conspiração e informações falsificadas vêm ganhando complexidade e escala em um ambiente em rede e polarizado. Antes disso, na época da Guerra Fria, a antiga União Soviética se utilizava de técnicas de propaganda ${ }^{8}$ com o objetivo de fazer seus alvos agirem de acordo com os interesses do propagandista, sem perceberem que o estavam fazendo. A partir de 2008, essas técnicas começaram a ser adaptadas ao ambiente tecnológico digital de nosso século, até que em 2014, com a anexação da Crimeia à Federação Russa, surgiu uma nova abordagem deste modelo de propaganda, nomeada em um relatório do Departamento de Segurança Nacional da Rand ${ }^{9}$ como "firehose of falsehood" (ou "jato de falsidades"), em referência ao jato d'água provocado por uma mangueira de pressão, devido a suas características: o grande número de canais utilizados e mensagens distribuídas e a disposição em disseminar histórias parcialmente acuradas e mentiras de forma rápida, contínua, repetitiva e sem compromisso com a coerência ou com os fatos (PAUL; MATTHEWS, 2016, p.1).

Além dos canais não confiáveis e dos conteúdos deliberadamente falsificados, um problema adicional é a sustentação deliberada, por parte de políticos, de versões ilegítimas a respeito de fatos. Um caso emblemático aconteceu após a posse de Donald Trump como presidente dos Estados Unidos, em janeiro de 2017. Seu secretário de Imprensa, Sean Spicer, afirmou que um número recorde de pessoas havia assistido à cerimônia de posse em Washington. Logo em seguida a informação foi desmentida. Um apresentador da rede de televisão NBC questionou uma funcionária do alto escalão da Casa Branca, Kellyanne Conway, sobre a afirmação falsa, ao que ela respondeu que não se tratava de uma mentira, mas sim de "fatos alternativos". Para o linguista Jan Blommaert (2017), a declaração de Conway institucionalizou esse conceito, cujas origens estão ligadas à ascensão do que ele chama de "metapolítica da nova direita" (BLOMMAERT, 2017, p. 4). O fenômeno se caracteriza, segundo o autor, por quatro aspectos:

tradução livre, "referente a situação em que as pessoas estão mais propensas a aceitar um argumento baseado em suas emoções e crenças do que um baseado em fatos").

${ }^{8}$ Adotamos o termo "propaganda" especificamente para nos referirmos à divulgação de ideias ou doutrinas. No senso comum, a palavra muitas vezes se confunde com "publicidade", termo adotado quando se trata de promover produtos ou serviços.

${ }^{9}$ A Rand Corporation se define, no website da empresa, como "uma organização sem fins lucrativos que ajuda a melhorar as políticas e a tomada de decisões por meio de pesquisa e análise" (tradução livre). 
a) a desqualificação da racionalidade: os fatos racionais seriam uma ferramenta de "opressão" de uma elite de esquerda, enquanto os fatos alternativos seriam vivenciados pelas "pessoas comuns";

b) a moralização da "verdade": ao se jogar o foco nos agentes, ou seja, em quem enuncia as afirmações factuais, estas são descartadas, porque foram produzidas pelas "pessoas erradas" - a verdade torna-se uma questão de identidade;

c) o trabalho "ergóico": a criação de padrões que o autor chama de ergóicos (inspirado na racionalidade cartesiana do ergo, palavra em Latim que significa "logo" ou "por consequência"), ou seja, aqueles que relacionam pequenos incidentes, eventos ou fenômenos a padrões maiores.

d) o uso das características das redes sociais da internet: as interfaces das plataformas se baseiam em velocidade, frequência e intensidade, o que favorece a criação de padrões ergóicos em mensagens visuais.

Assim, os chamados "fatos alternativos" constituiriam uma forma de "verdade" autocontida, imune à refutação factual, uma vez que está ancorada não nos acontecimentos, mas em sua coerência com visões de mundo e definições identitárias de grupos ou de pessoas.

Porém, não são apenas políticas as motivações de quem se beneficia da desordem da informação, até porque, como mostra a Figura 1, ela é composta por diferentes elementos, com potenciais de dano e intenções maliciosas que variam da sátira mal interpretada à informação deliberadamente falsificada, criada com o intuito de prejudicar alguém (WARDLE; DERAKHSHAN, 2017, p.23). 


\section{Figura 1 - Tipos de desinformação}


Fonte: Projeto First Draft. Elaborado por Claire Wardle. Tradução livre.

Nesse sentido, uma visão complementar é oferecida por Paul Levinson (2018), que, ao analisar as chamadas "fake news" (termo adotado pelo autor) no contexto das eleições norte-americanas de 2016, afirma que diferentemente das notícias jornalísticas, cujo propósito é reportar fatos que aconteceram, as histórias falsas têm em sua essência o apelo às emoções, aproximando-se, portanto da propaganda, que tem como objetivo não informar, e sim influenciar.

Levinson argumenta que as histórias falsas também são criadas e disseminadas por motivações financeiras. Um exemplo disso ocorreu durante a campanha presidencial norte-americana de 2016, quando jovens macedônios descobriram uma forma de ganhar dinheiro criando sites para veicular histórias falsas e sensacionalistas sobre as eleições nos Estados Unidos. Nas semanas que antecederam a votação, havia mais de 100 sites pró-Trump com domínios registrados na cidade de Veles, cuja população é de 55 mil habitantes. Um desses jovens, identificado como "Boris" em uma reportagem da revista Vice, alega ter ganhado 16 mil dólares entre agosto e novembro de 2016, o equivalente a 43 vezes o valor do salário mínimo na Macedônia (GRASSEGER; KROGERUS, 2017).

A perspectiva de Levinson também interpreta o impacto das histórias falsas à luz de outro fenômeno trazido pelo ambiente das tecnologias de informação e 


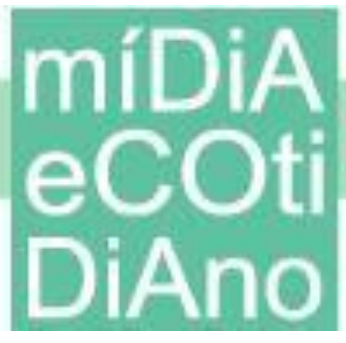

comunicação, que é a propensão das pessoas a buscar na internet as visões com as quais concordam mais, ou nas quais mais acreditam. O autor ressalva que esta característica humana precede a internet, tendo sido descrita pela teoria da dissonância cognitiva de Leon Festinger e, posteriormente, por Marshall McLuhan, que introduziu o conceito de "Narciso como narcose", ou o entorpecimento que sofremos perante os reflexos midiáticos de nossas ideias e sentimentos (LEVINSON, 2016, posição Kindle 237). A adoção contínua de tecnologias que são extensões dos sentidos levaria ao "adormecimento subliminar em relação às imagens de nós mesmos" (MCLUHAN, 2007, p.64) e, com isso, passaríamos a nos relacionar com essa tecnologia como servomecanismos, adorando-as como se adoravam ídolos.

\section{Educação midiática e jornalismo}

Em paralelo a este cenário da desordem da informação, o uso das mídias tradicionais pelos/as jovens como fonte de informação tem sofrido declínio em comparação com as plataformas da internet. Segundo a Pesquisa Brasileira de Mídia 2016, metade dos jovens de 16 a 24 anos apontam a internet como o veículo mais usado para consumir notícias (na faixa de 16 e 17 anos, 51\%; na de 18 a 24 anos, 50\%). Porém, ao mesmo tempo em que o uso das redes sociais da internet se consolida entre os jovens, a informação veiculada por esses meios nem sempre é confiável. Para Wardle e Derakhshan (2017), a diferenciação entre informações falsas e verdadeiras na internet vem se tornando cada vez mais difícil. O fato de um site de um veículo jornalístico e outro de teorias da conspiração terem a mesma aparência faz com que as pessoas passem a depender de amigos e familiares para determinar a veracidade - ou não - de uma notícia.

Os problemas trazidos pela desinformação também afetam a própria credibilidade do jornalismo. Fidalgo e Canavilhas (2009) sintetizam os desafios enfrentados pelo jornalismo profissional a partir da consolidação do telefone celular como principal meio de acesso às notícias em três principais pontos: agora as pessoas estão sempre ao alcance da notícia; elas chegam por um meio que é também usado para a comunicação pessoal; e este meio serve tanto para receber quanto para transmitir informações. Assim, "a produção de conteúdos não obedecerá a um esquema vertical, de poucos produtores para muitos consumidores, mas seguirá por um modelo de partilha $\mathrm{P} 2 \mathrm{P}$ 


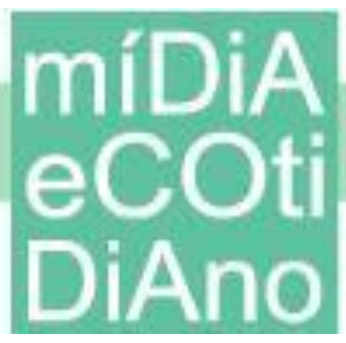

ou de web 2.0, em que quem consome também produz" (FIDALGO; CANAVILHAS, 2009, p.117).

Em relatório da Unesco sobre a relação entre o jornalismo e a desinformação no ambiente midiático atual, Abu-Fadil (2018) afirma que a educação midiática, conceito que será detalhado mais adiante, pode ajudar as pessoas a perceberem que mesmo notícias autênticas são sempre construídas e consumidas a partir de enquadramentos que dão sentido aos fatos, a partir de pressupostos ideológicos e identidades culturais (ABUFADIL, 2018, p.78). A autora traz, ainda, a citação da pesquisadora Rouba El Helou: "[a] educação midiática ajuda as pessoas a encontrar o equilíbrio entre a confiança nas fontes de notícias e a desconfiança necessária para questioná-las" (ABU-FADIL, 2018, p. 79). Em suma, o que pesquisadores do tema têm apontado é que como boa parte da informação disseminada no ambiente digital chega a nós por meio de variadas tecnologias (mídias impressas, audiovisuais, digitais e móveis), a habilidade de leitura crítica dos diferentes tipos de mídias se tornou essencial.

Além disso, segundo Mark Deuze (2016), todos os indivíduos precisam desenvolver habilidades específicas para processar a grande quantidade de informações que recebemos, no que ele chama de sociedade redacional, ou seja, aquela em que práticas editoriais "não podem ser consideradas algo exclusivo de um grupo profissional particular como jornalistas empregados em organizações jornalísticas" (DEUZE, 2016, p.9). A curadoria de informações, portanto, não é mais atividade restrita a jornalistas, uma vez que usuários de redes sociais da internet passam a usar técnicas semelhantes às jornalísticas mas nem sempre sabem lidar com suas consequências. Embora os/as jovens da era digital tenham amplo acesso a dispositivos e plataformas, isso não necessariamente se traduz em competências de news literacy, já que estas são socialmente adquiridas.

Para tentar mitigar os efeitos desse problema, a Stony Brook University, em Nova York, desenvolveu um currículo específico de news literacy em sua escola de Jornalismo, com foco no desenvolvimento de competências de leitura crítica que possibilitem avaliar a confiabilidade e credibilidade de uma informação, seja em veículos da mídia impressa, televisão ou internet. Segundo o site institucional do programa, "[e]sta é uma competência particularmente importante na era digital, uma vez que todos lutamos 


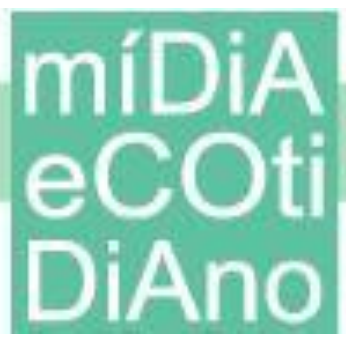

para lidar com a sobrecarga de informações e a dificuldade de determinar a autenticidade de relatos ${ }^{10 "}$ (CENTER FOR NEWS LITERACY, 2016).

Um exemplo que ilustra a relação entre a aquisição de competências de leitura crítica das mídias e a minimização dos efeitos da desinformação pode ser observado a partir das conclusões de uma pesquisa conduzida por Kahne e Bowyer (2016). Em um amplo estudo realizado com estudantes norte-americanos de 15 a 27 anos, os autores testaram a capacidade dos jovens de diferenciar notícias verdadeiras de falsas, e concluíram que apenas ter uma boa formação política não aumenta a possibilidade de distinguir uma da outra. Ao contrário do que se poderia esperar, os/as jovens mais politizados/as tenderam a acreditar mais fortemente em argumentos que confirmassem suas opiniões, fossem eles falsos ou verdadeiros: "[d]iferentemente dos desinformados, que eram mais suscetíveis a aprender com a exposição a novas informações, os malinformados tinham confiança de que estavam certos, resistiam à informação factualmente correta e usavam a má informação para formar suas preferências políticas" (KAHNE; BOWYER, 2016, p. 8-9).

Em 2011, a Unesco publicou um documento com diretrizes para a difusão da chamada alfabetização midiática na educação, juntando a este o conceito de alfabetização informacional. A publicação desse documento se inseria em um contexto de preocupação com o poder potencial das empresas de comunicação, na medida em que as mediações realizadas pelos produtores dos conteúdos midiáticos nem sempre são visíveis a quem consome esses conteúdos. O relatório, publicado no Brasil em 2013, defende, ainda, a chamada alfabetização midiática e informacional como forma de dar aos/às leitores/as e cidadãos/ãs as habilidades necessárias para que eles/as mesmos/as cobrem das diferentes mídias informações de qualidade:

As competências adquiridas pela alfabetização midiática e informacional podem equipar os cidadãos com habilidades de raciocínio crítico, permitindo que eles demandem serviços de alta qualidade das mídias e de outros provedores de informação. Conjuntamente os cidadãos fomentam um ambiente propício em que as

10 Tradução livre. No original: This is a particularly important skill in the Digital Age, as everyone struggles to deal with information overload and the difficulty in determining the authenticity of reports. 
mídias e outros provedores de informação possam prestar serviços de qualidade (WILSON et al., 2013, p.16).

Já nos anos 1970, Inglaterra, Austrália e Canadá desenvolviam ações no sentido do que a Unesco chama de media literacy. No final dos anos 1990, os EUA implantaram a disciplina em todos os programas federais de ensino. No entanto, apesar de ter sua importância reconhecida mundialmente, tanto a conceituação quanto a nomenclatura para essas competências ainda não apresentam consenso entre acadêmicos e instituições. Dois anos antes do relatório da Unesco, um estudo realizado para a Comissão Europeia (CELOT; PÉREZ-TORNERO, 2009) usa a expressão literacia midiática, classificando o fenômeno como um processo comunicativo de interação entre diferentes agentes em um ambiente que está mudando rapidamente. $\mathrm{O}$ estudo mostrou ser impossível, por enquanto, estabelecer uma definição universal e definitiva para o termo, que pode ser entendido, de uma forma ampla, como a capacidade individual de interpretar, de forma autônoma e crítica, o fluxo, o conteúdo, o valor e os efeitos da mídia em todas suas formas. Para os autores, o objetivo final da literacia midiática é o desenvolvimento do entendimento crítico e da participação cidadã, por exemplo, através do empoderamento e da interação dos indivíduos na vida sócio-política através da mídia. E alertam que a literacia midiática não é apenas uma questão técnica ou acadêmica. Ao contrário, ela tem mais a oferecer como uma ferramenta de análise sócio-política.

No Brasil, iniciativas de convergência entre educação e meios de comunicação datam dos anos 1930, com a fundação da Rádio Escola Municipal do Rio de Janeiro. Nos anos 1960, Paulo Freire destacava o caráter dialógico comunicacional da educação (FIGARO, 2015). Durante a década de 1980, a preocupação com a disseminação e a influência dos meios de comunicação sobretudo sobre as crianças levou ao surgimento de ações e discussões sobre a necessidade de uma educação para as mídias. A União Cristã Brasileira de Comunicação (UCB) criou o Projeto de Leitura Crítica da Comunicação (LCC) e foram realizados Seminários Latino-americanos de educação para a televisão, apoiados pela Unesco no Chile, Argentina e Brasil (SOARES, 2008; 2014).

Nos anos 1990, sugiram no Brasil outros projetos que visavam o desenvolvimento da leitura crítica das notícias veiculadas pelos meios de comunicação de massa, como o Observatório da Imprensa (1996) e o site Newsware (1999). Desde o 
início da década, ações articuladas da ECA/USP culminaram na criação da Revista Comunicação \& Educação (1994) e do Núcleo de Comunicação e Educação (1996), nos quais foi sendo consolidado o conceito de educomunicação. A educomunicação entende que a media literacy, ou educação para os meios, é apenas um dos aspectos de uma formação mais ampla que passa, também, pela apropriação das técnicas e uso dos meios para elaboração e disseminação da expressão de crianças, jovens e adultos, buscando-se, assim, fortalecer um ecossistema comunicativo aberto. Por isso, pesquisadores e profissionais de educomunicação entendem que o documento da Unesco sobre alfabetização midiática tem limitações, uma vez que suas recomendações são apenas parte do que é uma questão cultural mais abrangente (SOARES, 2014).

Assim, podemos ver que a educação midiática é um conceito amplo, que abrange mas não se limita à chamada news literacy. Apesar de ressaltarmos a importância do trabalho da educomunicação, entendemos a urgência de se desenvolverem projetos específicos em alfabetização midiática para notícias, devido ao crescimento exponencial da disseminação de desinformação pelas redes sociais da internet.

Uma das mais importantes pesquisadoras sobre o tema, a norte-americana Renée Hobbs, em artigo publicado em co-autoria com Amy Jensen, define:

[A] educação midiática requer questionamento ativo e pensamento crítico a respeito das mensagens que criamos e recebemos; é uma conceituação expandida de alfabetização; desenvolve competências para aprendizes de todas as idades e requer uma prática integrada, interativa e repetida; seu propósito é desenvolver participantes informados, reflexivos e engajados, essenciais para uma sociedade democrática; as mídias são vistas como parte da cultura e funcionam como agentes de socialização; e as pessoas usam suas competências, crenças e experiências para produzir sentidos para as mensagens das mídias ${ }^{11}$ (HOBBS; JENSEN, 2009, p.7).

11 Tradução livre. No original: [M]edia literacy education requires active inquiry and critical thinking about the messages we receive and create; that MLE is an expanded conceptualization of literacy; that it builds skills for learners of all ages and requires integrated, interactive, and repeated practice; that the purpose of MLE is to develop informed, reflective, and engaged participants essential to a democratic society; that media are part of culture and function as agents of socialization; and that people use their own skills, beliefs and experiences to construct meanings from media messages. 
As autoras enfatizam, ainda, o papel da educação midiática no apoio à cidadania ativa e democrática, em oposição a simplesmente criar consumidores/as bem informados/as de mídias e culturas de massa.

Em palestra no $19^{\circ}$ Congresso da Media Ecology Association, realizado em 2018, na Universidade do Maine, Hobbs apresentou um quadro-resumo em que demonstra a evolução das iniciativas de educação midiática desde o início do século XX, em contraposição ao contexto educacional de cada época (ver Tabela 1). Segundo o levantamento histórico feito pela autora, os anos 2010 se caracterizam pelo ganho de relevância de questões ligadas à cidadania digital, o que tornou necessário que a educação midiática passasse a abranger o desenvolvimento de competências para combater a desinformação.

Tabela 1 - Histórico da educação midiática nos Estados Unidos

\begin{tabular}{|c|c|c|}
\hline Década & Contexto educacional & Iniciativas predominantes \\
\hline 1930 & $\begin{array}{c}\text { Distinção entre Literatura Clássica } \\
\text { e Contemporânea }\end{array}$ & Como reconhecer e resistir à propaganda \\
\hline 1950 & Surgimento da televisão educativa & Surgimento dos Estudos de Cinema \\
\hline 1960 & $\begin{array}{c}\text { A cultura popular chega à sala de } \\
\text { aula }\end{array}$ & Análise crítica da propaganda \\
\hline 1970 & $\begin{array}{c}\text { Jornalismo escolar e produção de } \\
\text { vídeo }\end{array}$ & Foco nos efeitos da mídia \\
\hline 1980 & Filme como literatura & $\begin{array}{l}\text { Contexto cultural, economia política e } \\
\text { processos de interpretação }\end{array}$ \\
\hline 1990 & Novas literacias & O surgimento da mídia jovem \\
\hline 2000 & EdTech & Cultura participativa \\
\hline 2010 & Cidadania digital e credibilidade & $\begin{array}{c}\text { Fake News (sic), privacidade, capitalismo } \\
\text { de plataformas }\end{array}$ \\
\hline
\end{tabular}

Fonte: Palestra de Renee Hobbs na $19^{\text {th }}$ Media Ecology Association Convention, University of Maine, junho de 2018 (informação verbal). Elaboração das autoras.

Em linha com essa preocupação, o Projeto Information Literacy, da Knight Foundation, conduziu uma pesquisa com estudantes universitários norte-americanos entre 2017 e 2018. Segundo o relatório que consolida os achados da pesquisa, 36\% dos respondentes acreditam que a ameaça das histórias falsas fez com que desconfiassem da credibilidade de todas as notícias, e $45 \%$ não se sentiam confiantes para diferenciar "notícias verdadeiras" de "notícias falsas" (HEAD et al., p.15). 
No Brasil, começam a surgir, ainda de forma incipiente, iniciativas de educação midiática com foco específico em notícias. A inclusão das competências ligadas à cultura digital na Base Nacional Comum Curricular (BNCC), que está em fase de implantação no Brasil ${ }^{12}$, motivou a produção de materiais didáticos sobre o tema. Recentemente, o Instituto Palavra Aberta lançou o programa EducaMídia, voltado à capacitação de professores, com apoio do Google.org e em parceria com diversas associações e organizações ligadas ao campo jornalístico. Vale observar que o investimento da Google na educação midiática para notícias pode indicar um interesse da corporação em se antecipar a possíveis questionamentos sobre a responsabilidade das plataformas digitais sobre os conteúdos falsos disseminados por meio delas, a exemplo do que vem acontecendo com o Facebook nos casos recentes em que o CEO da empresa, Mark Zuckerberg, foi convocado a depor no senado norte-americano e no parlamento europeu.

\section{Análise preliminar sobre iniciativas das escolas}

Com o objetivo de identificar se as escolas brasileiras estão dando importância ao tema, e se há iniciativas visando promover a educação midiática para notícias planejadas ou em curso, realizamos uma pesquisa tipo survey entre os dias 29 de agosto e 28 de setembro de 2019, com professores/as da educação básica por meio da ferramenta on-line Google Forms, em formulário divulgado em redes sociais da internet e compartilhado em grupos de WhatsApp. O número de respostas coletadas foi baixo, com um total de 43 participantes de cinco estados brasileiros. No entanto, a pouca adesão, apesar dos esforços de divulgação em redes sociais da internet e por meio do aplicativo de troca de mensagens instantâneas WhatsApp, pode ser explicada pelo comentário que recebemos de uma informante. Segundo a profissional, embora o questionário fosse totalmente anônimo, ou seja, não era coletado nenhum dado pessoal que permitisse a identificação do/a respondente (nome ou e-mail, por exemplo), a natureza das perguntas poderia expor o/a professor/a a eventuais punições ou retaliações nas instituições em que trabalham. A informante declarou, ainda, que "há perguntas qualitativas e algumas bem

\footnotetext{
12 Mais informações sobre a BNCC estão disponíveis em: <http://basenacionalcomum.mec.gov.br/>.
} 


\section{míDiA

'delicadas'... Acho difícil um professor, no atual clima, responder sem saber quem está perguntando". Vale ressaltar que todas as informações das autoras foram incluídas no formulário, sem, no entanto, alcançar um resultado mais robusto no que diz respeito ao número de respondentes.

Assim, consideramos que a baixa adesão à pesquisa é, em si, uma informação relevante sobre o quadro atual das escolas de educação básica no Brasil, pois retrata uma situação em que há temor por retaliações e preocupação com diversos fatores alheios à sala de aula, tais como problemas de segurança pública, dificuldades com a disciplina dos alunos e outros. Apesar disso, abrimos caminhos para pensar em algumas questões suscitadas a partir das poucas respostas que obtivemos.

A principal delas é que foi possível constatar que mais da metade dos/as respondentes (24 de 43 respostas) consideram muito importante desenvolver ações específicas de educação midiática na(s) escola(s) em que trabalham (ver Figura 2). No entanto, ao responder sobre os problemas que mais preocupam as pessoas tanto acima quanto abaixo na hierarquia, bem como seus pares, nenhum/a indicou questões ligadas aos desafios da educação na era digital. Os principais problemas apontados foram relacionados à segurança pública (maior preocupação de professores da rede pública municipal), a agressividade ou indisciplina dos alunos (rede estadual), a falta de recursos (institutos federais) e a inadimplência e evasão escolar (rede particular). Já nas perguntas específicas sobre o uso das plataformas digitais pelos alunos, um/a professor/a de instituto federal mencionou ser importante os alunos "não se tornarem meros reprodutores de informação", em linha com as recomendações de Hobbs e Jensen. Um/a professor/a da rede municipal do Rio de Janeiro apontou especificamente "informações falsas" como a principal preocupação dos/as colegas em relação ao uso das plataformas digitais pelos estudantes. De resto, a maior parte dos respondentes falou sobre questões mais gerais ligadas ao uso excessivo de dispositivos digitais em sala de aula para fins não pedagógicos, falta de equipamentos, exposição indevida dos estudantes nas redes sociais da internet e outros temas não relacionados à educação midiática para notícias. 


\title{
Figura 2 - Importância da educação midiática nas escolas
}

\begin{abstract}
Em sua opinião, qual é a importância de desenvolver ações específicas de educação midiática na(s) escola(s) em que você trabalha, em uma escala em que 1 é o menos importante e 5 o mais importante?
\end{abstract}

41 respostas

30



\section{Considerações finais}

Ao relacionar a análise de estudiosos sobre a desinformação e seus efeitos sobre a vida social e o debate público às iniciativas dos defensores da educação midiática, podemos constatar que o desenvolvimento de competências específicas para leitura crítica das mídias é fundamental para combater a desordem da informação. A educação midiática, portanto, mostra-se como um caminho eficaz para capacitar crianças e jovens imersos em um mundo em transformação, em que todos somos impactados por novas formas de nos relacionar e de nos informar.

Diante deste cenário, é curioso que a pesquisa realizada para a elaboração deste artigo, embora com uma amostra reduzida de respondentes, sinalize pouca preocupação com a questão específica da educação midiática para notícias, ou news literacy. Vale destacar a necessidade de realizar nova pesquisa buscando obter uma amostra mais ampla, de forma a obter resultados mais significativos.

No que diz respeito à amostra analisada, contudo, pode-se dizer que é compreensível que problemas de maior impacto cotidiano, como a segurança e a falta de recursos, sejam apontados como as principais preocupações dos/as professores/as. No que diz respeito às questões diretamente ligadas ao uso de plataformas digitais pelos 


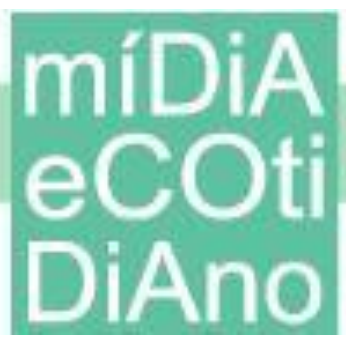

estudantes também aparecem outros pontos de atenção, relacionados à privacidade e ao uso excessivo dos dispositivos. Todos esses assuntos são de fato importantes e devem ser objeto da educação midiática de forma mais ampla; no entanto, parece haver uma preocupação crescente em relação à educação midiática específica para leitura crítica de fontes de informação, no que poderíamos considerar como ações para promover a news literacy no Brasil.

Em nosso entendimento, é preciso começar a relacionar a necessidade de educação midiática a um contexto mais amplo. Estudos da ecologia das mídias defendem que estaríamos vivendo a sociedade da conexão restaurada (PETTITT, 2012). O uso da internet por dispositivos móveis e a ampliação progressiva dos ambientes de socialização on-line estariam trazendo de volta características próprias da Idade Média. Nas sociedades medievais, como na nossa, a lógica da conexão é mais importante que o conteúdo. As fronteiras entre o que é público e o que é privado são pouco nítidas, não há uma demarcação clara; as identidades são múltiplas e não territoriais; e há um incremento dos apelos à emotividade em detrimento da racionalidade como forma de pensar e de organizar a vida social.

Assim, de acordo com a abordagem do medievalista dinamarquês Thomas Pettitt, os principais pilares da civilização moderna, como a Reforma Protestante, a Renascença e a Revolução Científica, foram o resultado da era da impressão, chamada por McLuhan de Galáxia de Gutemberg. Por isso, para ele, a era da conexão restaurada tornaria possível a restauração da fé cega em lideranças - fenômeno já em curso, que, em alguma medida, explica a eficiência da tática do "jato de falsidades" para disseminação da desinformação.

Dessa forma, embora os resultados da pesquisa mostrem que a desinformação aparece como uma preocupação menor em relação a outras questões de mais apelo, porque mais visíveis no cotidiano escolar, essa talvez seja uma das questões mais urgentes que a escola - como instituição - deve enfrentar. Trata-se de um aspecto fundamental de um panorama mais amplo, em que se anuncia a prevalência da conexão em detrimento do conteúdo. A escola é uma instituição iluminista, que se ergue sobre o paradigma da ciência e do humanismo racionalista. Sem a educação midiática, é o próprio sistema escolar que se coloca em risco. Não por acaso, temos testemunhado discursos que atacam 
as ciências como instância legitimada de conhecimento. A desinformação e a deslegitimação das ciências são manifestações de um mesmo fenômeno.

É preciso, portanto, que a comunidade escolar assuma a dianteira neste processo, sob pena de as futuras gerações sofrerem as consequências de viver em uma sociedade em que não se sabe diferenciar fatos de opiniões; ou, de modo ainda mais dramático, no qual a vida na "bolha dos filtros" (PARISER, 2012) acabe por esvaziar as ciências como um conhecimento compartilhado socialmente e, por consequência, a escola como instância em que este conhecimento é ensinado às futuras gerações.

\section{Referências}

19th MEA CONVENTION. Orono, EUA, 2018. Palestra de Renee Hobbs (featured speaker). Anotações das autoras.

ABU-FADIL, Magda. Combatting disinformation and misinformation through Media and Information Literacy (MIL). In: IRETON, Cherilyn; POSETTI, Julie. Journalism, 'Fake News' \& Disinformation: handbook for Journalism Education and Training. Paris: UNESCO, 2018. 128 p. (UNESCO Series on Journalism Education).

BRAGA, Adriana; AGUIAR, Leonel; BERGAMASCHI, Mara. O chão de fábrica da notícia: contribuições para uma economia política da práxis jornalística. Intercom-RBCC, v. 37, n. 1, p. 111-131, 2014. Disponível em: 〈http://www.scielo.br/pdf/interc/v37n1/a06v37n1.pdf〉. Acesso em: 28 fev. 2019.

BLOMMAERT, Jan. Ergo: Exploring the world of alternative facts. Ctrl+Alt+Dem, [s.1.], 19 set. 2018. Disponível em: <https://alternative-democracy-research.org/2018/09/19/ergo/>. Acesso em: 01 mai. 2019.

CELOT, Paolo; PÉREZ-TORNERO, José Manuel. Study on assessment criteria for media literacy levels. Brussels: EAVI - European Association for Viewer's Interests, 2009.

CENTER FOR NEWS LITERACY. Website. Disponível em:

<https://www.centerfornewsliteracy.org/what-is-news-literacy/>. Acesso em: 30 set. 2019.

DARNTON, Robert. The True History of Fake News. The New York Review of Books, New York, 13 fev. 2017. Disponível em: <https://www.nybooks.com/ daily/2017/02/13/the-truehistory-of-fake-news/>. Acesso em: 22 jan. 2018.

DEUZE, Mark, WITSCHGE, Tamara. O que o Jornalismo está se tornando. Parágrafo, v. 4, n. 2, jul.-dez. 2016.

FIDALGO, António; CANAVILHAS, João. Todos os Jornais no Bolso: pensando o jornalismo na era do celular. In: RODRIGUES, Carla (Org.). Jornalismo on-line: modos de fazer. Rio de Janeiro: Editora PUC-Rio; Porto Alegre: Editora Sulina, 2009.

FIGARO, Roseli. Paulo Freire, comunicação e democracia. Comunicação \& Educação, v. 20, n. 1, p. 7-5, jan./jun. 2015. 
GRASSEGGER, Hannes; KROGERUS, Mikael. The Data That Turned the World Upside Down. Vice, 28 jan. 2017. Disponível em: <https://www.vice.com/en_us/article/mg9vvn/howour-likes-helped-trump-win>. Acesso em: 28 fev. 2019.

HEAD, Alison J.; WIHBEY, John; TAKIS METAXAS, P.; MACMILLAN, Margy; COHEN, Dan. How Students Engage with News: Five Takeaways for Educators, Journalists, and Librarians. Project Information Literacy Research Institute. [s.1.], 2018. Disponível em: $<$ https://library.educause.edu/resources/2018/10/how-students-engage-with-news-fivetakeaways-for-educators-journalists-and-librarians>. Acesso em: 30 set. 2019.

HOBBS, Renee; JENSEN, Amy. The Past, Present, and Future of Media Literacy Education. Journal of Media Literacy Education. v. 1. n. 1, p. 1-11. 2009. Disponível em: <https://digitalcommons.uri.edu/jmle/vol1/iss1/1/>. Acesso em: 30 set. 2019.

KAHNE, Joseph; BOWYER, Benjamin. Educating for Democracy in a Partisan Age: confronting the challenges of motivated reasoning and misinformation. American Educational Research Journal. v. 54, n. 1, p. 3-34, Feb. 2017. Disponível em: <http://journals.sagepub.com/doi/full/10.3102/0002831216679817〉. Acesso em: 30 set. 2019.

LEVINSON, Paul. Fake News in Real Context. New York: Connected Editions, 2016. Edição Kindle.

MCLUHAN, Marshall. O amante de "gadgets": Narciso como narcose. In: Os meios de comunicação como extensões do homem. São Paulo: Cultrix, 2007.

PARISER, Eli. O filtro invisível: o que a internet está escondendo de você. Rio de Janeiro: Jorge Zahar Editor, 2012.

PAUL, Christopher; MATTHEWS, Miriam. The Russian "Firehose of Falsehood" Propaganda Model: why it might work and options to counter it. Santa Monica: Rand Corporation, 2016, 16 p. Relatório Técnico. Disponível em: <https://www.rand.org/pubs/perspectives/PE198.html>. Acesso em: 12 dez. 2018.

PETTITT, Thomas. Bracketing the Gutenberg parenthesis. Explorations in Media Ecology, v. 11, n. 2. pp. 95-114, set. 2013.

REUTERS Institute for the Study of Journalism. Reuters Institute Digital News Report 2018. Relatório técnico. Disponível em: <www.digitalnewsreport.org>. Acesso em: 30 set. 2019.

REUTERS Institute for the Study of Journalism. Reuters Institute Digital News Report 2019. Relatório técnico. Disponível em: <www.digitalnewsreport.org>. Acesso em: 30 set. 2019.

SECRETARIA ESPECIAL DE COMUNICAÇÃO SOCIAL DA PRESIDÊNCIA DA REPÚBLICA DO BRASIL. Pesquisa Brasileira de Mídia 2016: hábitos de consumo de mídia pela população brasileira. Brasília: [s.n.]. Relatório técnico. Disponível em: <http://www.pesquisademidia.gov.br>. Acesso em: 30 set. 2019.

SOARES, Ismar de Oliveira. Educomunicação e Educação Midiática: vertentes históricas de aproximação entre Comunicação e Educação. Comunicação \& Educação, v. 8, n. 3, p. 39-52, set./dez. 2009.

SOARES, Ismar de Oliveira. Quando o Educador do Ano é um educomunicador: o papel da USP na legitimação do conceito. Comunicação \& Educação, v. 19, n. 2, p. 15-26, jul./dez. 2014. 
WILSON, Carolyn; GRIZZLE, Alton; TUAZON, Ramon; AKYEMPONG, Kwame; CHEUNG, Chi Kin. Alfabetização midiática e informacional: currículo para formação de professores. Brasília: UNESCO, UFTM, 2013.

WARDLE, Claire; DERAKHSHAN, Hossein. Information Disorder: Toward an interdisciplinary framework for research and policy making. Council of Europe Report, 2017.

WHITE, David Manning. O gatekeeper: uma análise de caso na seleção de notícias. In: TRAQUINA, Nelson. (Ed.). Jornalismo: questões, teorias e "estórias". Lisboa: Vega, 1993. p. $61-73$. 